\title{
ACUTE PERFORATION OF A GASTROJEJUNAL ULCER: A RARE CASE REPORT
}

\author{
Mohammed Faheem Inamdar ${ }^{1}$, Shekappa C. Malagimani²
}

\section{HOW TO CITE THIS ARTICLE:}

Mohammed Faheem Inamdar, Shekappa C. Malagimani. “Acute Perforation of a Gastrojejunal Ulcer: A Rare Case Report". Journal of Evolution of Medical and Dental Sciences 2014; Vol. 3, Issue 46, September 22; Page: 11302-11304, DOI: 10.14260/jemds/2014/3475

\begin{abstract}
Recurrent postoperative ulceration after peptic ulcer surgery has become an increasingly uncommon problem in the last decade. Primary treatment with H. pylori eradication, NSAIDs with fewer gastrointestinal side effects, and proton pump inhibitors have decreased the incidence of peptic surgery.[1] Pain and hemorrhage are the most common symptoms of postoperative recurrent ulceration, each occurring in about $40 \%$ of patients.[2] Obstruction is the presenting symptom in approximately $10 \%$ of patients. Rarely, recurrent ulceration presents as a free perforation.
\end{abstract}

KEYWORDS: Gasrojejunal ulcer, perforative peritonitis, Stomal ulcers.

CASE REPORT: A 46 year old male presented with acute onset pain initially in the upper abdomen which later became diffuse. He also had vomiting 1 to 2 episodes and abdominal distension. There was no history of trauma, fever, chest pain. There was history of previous surgery for peptic ulcer 6 years back without any documentation. On examination pulse rate was 90/min, B.P 110/70 $\mathrm{mmHg}$, respiratory rate $20 / \mathrm{min}$ and was febrile.

On per abdominal examination there was a vertical midline scar mark. Abdomen was distended with diffuse tenderness. Muscle guarding and rigidity were present with obliteration of liver dullness. Bowel sounds were absent and hernial orifices were normal. P.R examination was normal. Chest $\mathrm{x}$ ray showed gas under the right dome of diaphragm. Laboratory investigations were normal except for mild hypernatremia. After brief resuscitation patient was planned for exploratory laparotomy. A midline laparotomy was done after excision of previous scar. On exploration significant amount of pus was present which was sampled.

All the adhesions were released and bowel was traced. A posterior gastrojejunostomy was present and perforation of $1.5 \mathrm{~cm}$ was present near it on the gastric wall. Biopsy was taken. Ryle's tube was noted and placed in the efferent loop. As the general condition was poor the perforation was repaired and a feeding jejunostomy was done. Thorough peritoneal lavage was done and abdominal drain kept. Postoperatively the course was uneventful and feeding jejunostomy removed after patient started oral feeds.

DISCUSSION: Stomal ulcers are infrequent today as the numbers of gastrojejunostomy and vagotomy have fallen due to the success of medical line of management. Stomal ulcers occur after a gastroenterostomy or a gastrectomy of the Bill Roth II type. The ulcer is usually found on the jejunal side of the stoma. ${ }^{[3]}$ The jejunal loop is exposed to the gastric acid, so the ulcer is usually present on the jejunal side. Stomal ulcers are infrequent today as the numbers of gastrojejunostomy and vagotomy have fallen due to the success of medical line of management. 
A study showed higher incidence of marginal ulcers in the ante colic limb than the retro colic limb after laparoscopic gastric bypass. ${ }^{[4]}$ In a review of literature, of a author[5] found 93 authentic reports of acute perforation in gastrojejunal ulcers and stated that usually the interval between the performance of gastrojejunostomy and acute perforation of gastrojejunal ulcer varied from 5 days to 18 years.[5] In our case the patient presented after 6 years and the ulcer was found to be on the gastric wall near the gastrojejunostomy.

\section{REFERENCES:}

1. Zinner M J, Ashley S W. Maingot's Abdominal Operations: Stomach and Duodenum: $11^{\text {th }}$ ed., p.353

2. Schirmer BD, Meyers WC, Hanks JB, et al. Marginal ulcer: A difficult surgical problem. Ann Surg 1982; 195: 653 [PubMed: 7073362]

3. Russel RCG, Williams S. Norman, Bulstrode JK. Bailey \& Love's short practice of surgery: Stomach and Duodenum: 25 $5^{\text {th }}$ ed. 1058.

4. Lara riberio - Parenti, Konstantinos Arapis. Comparison of marginal ulcer rates between ante colic and retro colic laparoscopic roux-en-y Gastric Bypass. Obes Surg. 2014 [Springer Link10.1007/s11695-014-1392-x]

5. Toland CG, Thompson HL. Acute Perforation of Gastrojejunal Ulcer. Ann Surg 1936; 104: 827.

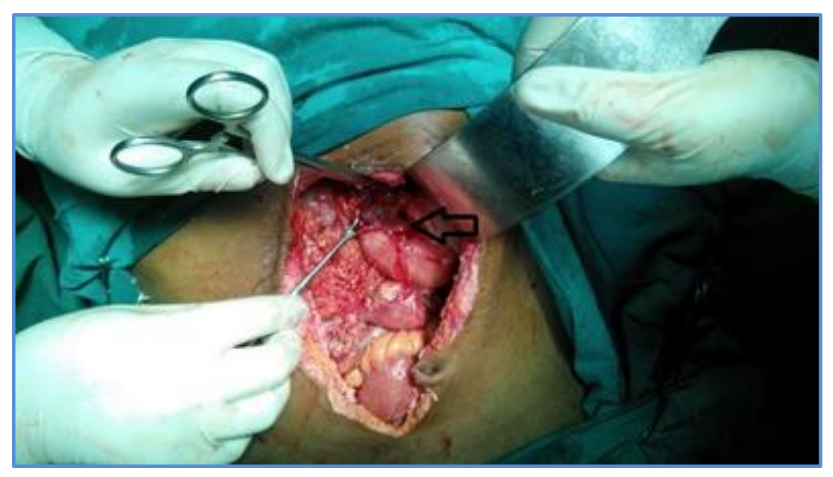

\section{Fig. 1: Perforated GJ ulcer}

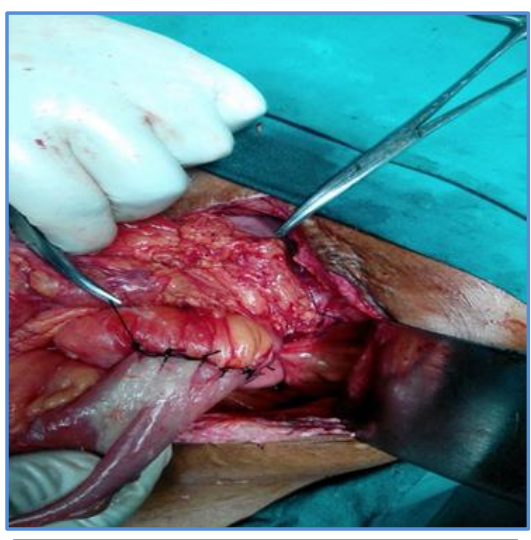

Fig. 2: Two layer closure of perforated ulcer

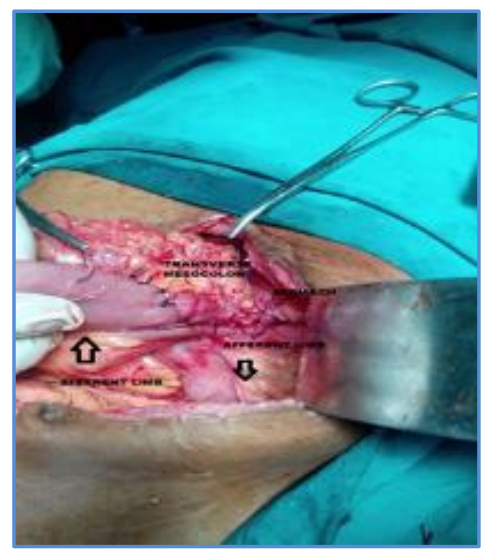

Fig. 3: Completed surgical procedure 


\section{CASE REPORT}

\section{AUTHORS:}

1. Mohammed Faheem Inamdar

2. Shekappa. C.

\section{PARTICULARS OF CONTRIBUTORS:}

1. Assistant Professor, Department of Surgery, VIMS, Bellary.

2. Associate Professor, Department of Surgery, VIMS, Bellary.

\section{NAME ADDRESS EMAIL ID OF} CORRESPONDING AUTHOR:

Dr. Shekappa C. M,

B/24, Staff Quarters, VIMS (OPD), Cantonment,

Bellary.

Email: doc_shekar@yahoo.com

Date of Submission: 08/09/2014.

Date of Peer Review: 09/09/2014.

Date of Acceptance: 16/09/2014.

Date of Publishing: 22/09/2014. 